\title{
Breast cancer in women who have taken contraceptive steroids
}

\author{
PHILIP N MATTHEWS， ROSEMARY R MILLIS， JOHN L HAYWARD
}

\begin{abstract}
The prognosis and clinical and pathological findings in 93 patients with breast cancer who had taken contraceptive steroids before diagnosis (study group) vere compared with those in 93 control patients, also with breast cancer, matched for age and parity. The tumours in the women in the study group were found to have more favourable clinical and histological features than those in the control group. When only patients who had been treated by radical mastectomy were considered, those who had taken contraceptive steroids survived significantly longer even when differences in nodal state were taken into account. Significantly more patients in the study group had a family history of breast cancer.

No evidence was found that taking oral contraceptive steroids had any harmful effect on tumour growth and spread, except possibly in patients with a close family history of breast cancer.
\end{abstract}

\section{Introduction}

The effects of steroidal contraceptives on the incidence and prognosis of breast cancer are still uncertain. Oestrogens are carcinogenic in many species of animals, and Hert $\mathrm{z}^{1}$ pointed out that since most compounds that are carcinogenic in man are also carcinogenic in animals the reverse is probably true. Large doses of oestrogens may cause regression of breast tumours in man, but small amounts may cause the growth rate to accelerate. ${ }^{2}$ In 1978, 54 million women were estimated to be using oral contraceptives. ${ }^{3}$ Several studies showed that women who have taken these products do not have an increased incidence of breast cancer, ${ }^{4-6}$ but controversy still remains over whether taking oral contraceptives affects the prognosis of the established disease. Most surgeons would advise their patients with recently diagnosed breast cancer not to take contraceptive steroids.

Spencer et $a l^{7}$ reported on 44 patients who had been taking oral contraceptives during the year preceding the diagnosis of breast cancer and compared these women with a control group of patients who had never taken oral contraceptives. They found no evidence that taking such products caused increased progression of disease. Since the preclinical phase of breast cancer may extend over many years, we carried out a further study of patients who had ever used steroidal contraceptives and report here our results.

\section{Patients and methods}

The study group comprised 93 women with breast cancer who presented at the breast unit at this hospital during 1968-77 and had not been included in the study of Spencer et al. ${ }^{7}$ They had been using contraceptive steroids for a median of 24 months (range 1 month to

Imperial Cancer Research Fund Breast Cancer Unit, Guy's Hospital, London SE1 9RT

PHILIP N MATTHEWS, FRCS, surgical registrar (present address: St George's Hospital, London SW17)

ROSEMARY R MILLIS, MRCPATH, pathologist

JOHN I HAYWARD, FRCS, director
17 years), and only 14 were known to have been taking the products during the year before diagnosis. They were matched by age and parity with patients in a control group who presented with breast cancer at about the same time but had never taken oral contraceptive steroids. The related history, clinical findings, histological findings, and recurrence and survival rates in the two groups were compared.

The clinical stage of each tumour was ascertained from details recorded at the first outpatient visit. Most patients with early breast cancer were treated by radical mastectomy (table I), but 11 patients in each group were treated by wide excision and radiotherapy to the residual breast and node fields. This treatment had been chosen by random sample as part of a clinical trial. ${ }^{8}$ Seven patients in the study

TABLE I-Primary treatment of tumours in study and control groups

\begin{tabular}{lcc}
\hline & $\begin{array}{c}\text { Study group } \\
(\mathrm{n}=93)\end{array}$ & $\begin{array}{c}\text { Controls } \\
(\mathrm{n}=93)\end{array}$ \\
\hline Radical mastectomy & 65 & 62 \\
Simple mastectomy + radiotherapy & 10 & 6 \\
Wide excision + radiotherapy & 11 & 11 \\
Radiotherapy only & 4 & 11 \\
Other & 3 & 3 \\
\hline
\end{tabular}

group and 14 in the control group presented with advanced disease and therefore did not undergo potentially curative operations. The tumours and lymph nodes were examined histologically in those patients treated by radical mastectomy. All the remaining patients underwent biopsy, except for three who had advanced disease.

The patients were followed up at regular intervals and none was lost to follow-up. A paired $t$ test was used to compare the clinical and histological findings. Life tables were drawn to show recurrences and survival in the two groups and the curves compared by the log-rank method.

\section{Results}

Related history-Table II shows the clinical features of the patients. The two groups were closely similar, except that significantly more women in the study group had a family history of breast cancer $\left(p<0.05, \chi^{2}=4 \cdot 18\right)$.

TABLE II-Clinical features in study and control groups, which were matched for age and parity. (Ranges given in parentheses)

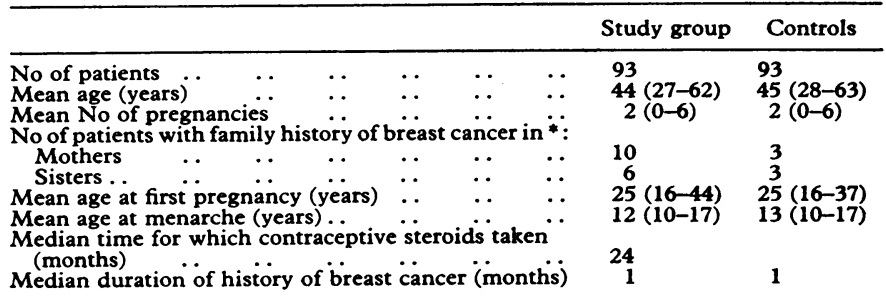

*No patient had a history of both mother and sister having breast cancer.

Clinical findings and treatment-Table III shows the clinical assessment of the tumours at the patients' first attendance, classified by the TNM system. Patients in the study group had significantly smaller tumours than those in the control group $(\mathrm{p}<0.01, t=-2.83)$ and generally a more favourable prognosis in terms of clinical presentation. 
TABLE III-Clinical assessment of breast tumour at first examination in study and control groups, according to TNM classification. (Figures are numbers of patients)

\begin{tabular}{|c|c|c|c|c|c|c|c|c|c|c|}
\hline & \multirow{2}{*}{$\begin{array}{c}\text { Mean } \\
\text { tumour } \\
\text { diameter } \\
\text { (and range) } \\
(\mathrm{cm})\end{array}$} & \multicolumn{5}{|c|}{$\mathrm{T}$} & \multicolumn{3}{|c|}{$\mathrm{N}$} & \multirow{2}{*}{$\frac{M}{1}$} \\
\hline & & 0 & 1 & 2 & 3 & 4 & $\begin{array}{c}0 \\
\text { and } \\
1 \mathrm{a}\end{array}$ & $\begin{array}{c}1 b \\
\text { and } \\
2\end{array}$ & 3 & \\
\hline $\begin{array}{l}\text { Study group } \\
\text { Controls }\end{array}$ & $\begin{array}{l}2 \cdot 4(0-9) \\
3 \cdot 2(0-10)\end{array}$ & 6 & $\begin{array}{l}43 \\
32\end{array}$ & $\begin{array}{l}39 \\
49\end{array}$ & $\begin{array}{r}4 \\
11\end{array}$ & $\begin{array}{l}1 \\
1\end{array}$ & $\begin{array}{l}85 \\
73\end{array}$ & $\begin{array}{r}8 \\
18\end{array}$ & 2 & 2 \\
\hline
\end{tabular}

Histological findings-Table IV gives the histological types of the primary tumours. Most were infiltrating duct carcinomas and were graded by the method originally described by Bloom and Richardson. ${ }^{\ominus}$ Tumours in the patients in the study group were of significantly lower grade (better differentiated) than those in the control group $(\mathrm{p}<0 \cdot 01$, $t=-2 \cdot 76)$.

TABLE IV-Histological features of primary tumours in study group and controls*

\begin{tabular}{|c|c|c|}
\hline Tumour type & Study group & Controls \\
\hline In situ duct & 8 & 3 \\
\hline Infiltration ductal & 75 & 80 \\
\hline Grade I & 14 & 7 \\
\hline Grade II & 43 & 42 \\
\hline Grade III & 18 & 31 \\
\hline Infiltrating lobular & 6 & 4 \\
\hline Medullary with lymphoid stroma & 4 & 3 \\
\hline
\end{tabular}

*Biopsy was not performed in three patients in the control group.

Nodal disease-Table $\mathrm{V}$ compares the axillary node metastasis in all patients treated by radical mastectomy. Patients in the study group had significantly less nodal disease than the controls $(\mathrm{p}<0.01$, $t=-2 \cdot 83$ ), although there was no difference in the mean number of diseased nodes per positive axilla.

TABLE $\mathrm{v}-$ Data from pathological examination of axillary lymph nodes in patients who underwent radical mastectomy

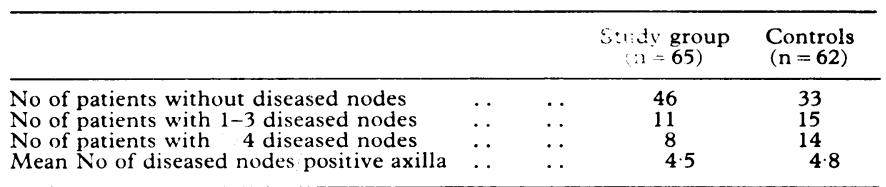

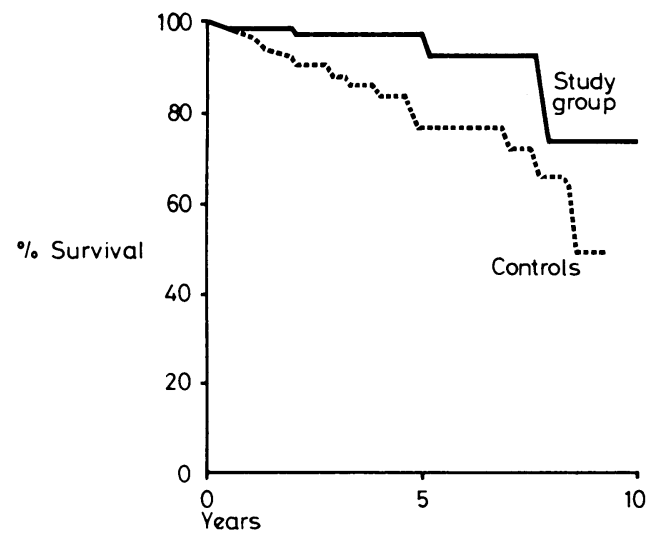

FIG 1-Survival of patients treated by radical mastectomy in study $(n=65)$ and control $(n=62)$ groups.

Recurrence and survival-Comparison of recurrence and survival in the two groups was complicated by several factors: more patients in the control group had presented with locally advanced disease, and not all patients with early disease had received the same treatment. We therefore compared only those with early breast cancer who had undergone radical mastectomy rather than include the other categories of treatments. Figure 1 shows the survival curves for the 65 patients in the study group and the 62 controls treated by radical mastectomy. Patients in the study group had significantly longer survival $(p<0.05$, $\left.x^{2}=4 \cdot 15\right)$. As more patients in the control group had diseased axillary nodes we compared patients in each group according to stage. Figure 2 shows the survival curves of the 46 patients in the study group and the 33 controls with pathological stage I tumours (no nodal disease).

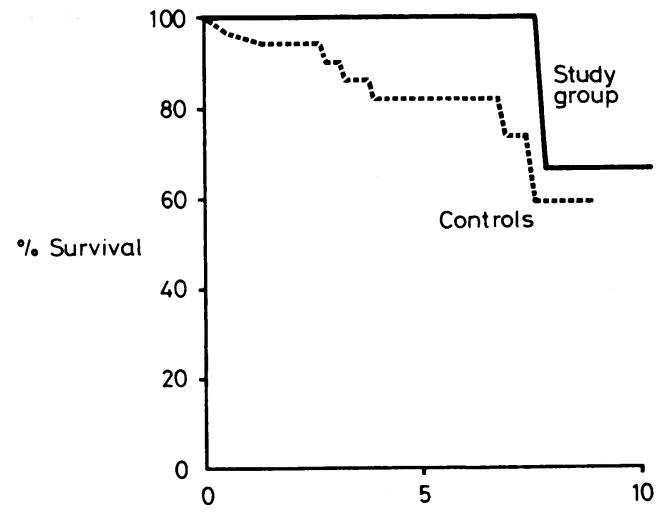

FIG 2-Survival of patients with pathological stage tumours treated by radical mastectomy in study $(n=46)$ and control $(n=33)$ groups.

Again those in the study group survived significantly longer $(p<0.04$ $\chi^{2}=4 \cdot 23$ ). There was no significant difference between the survival of patients with pathological stage II tumours (nodal disease) when the study group $(n=19)$ was compared with the controls $(n=29)$, although the study group appeared to be faring better. All deaths were due to breast cancer. When recurrence rates were compared the study group again fared better than the controls but the differences did not reach significance.

\section{Discussion}

In both the current study and the study of Spencer et al more women with breast cancer who had been taking contraceptive steroids had a family history of the disease than women in the control groups. This suggests several possibilities. One is that women with such a family history who are going to develop breast cancer some time during their life have the time of induction brought forward by taking contraceptive steroids. This would mean that in postmenopausal women there would subsequently be a dearth of breast cancer in those with a close family history who have taken such products. Alternatively, women with a family history of breast cancer may examine themselves more assiduously so that their tumour is discovered earlier. All epidemiological evidence points against a third hypothesis-namely, that contraceptive steroids actually cause cancer in these women-unless the converse is true-that is, that they prevent breast cancer in women without a family history. Lastly, both our findings and those of Spencer $e t \mathrm{al}^{7}$ may have occurred by chance and be due either to the small numbers studied or to some unknown bias. Indeed, no similar trend has been reported in other series. ${ }^{4-8}$

Breast cancers occurring in women with a family history of the disease may behave differently from those in other women, and the above phenomenon may be related to this in some way. In women with a family history there is an increased tendency towards bilateral disease and a higher incidence of medullary and lobular tumours has been suggested.10 Additionally, such patients have a $10-15 \%$ higher survival rate. ${ }^{11}$ This raises the question whether the trend towards a lower recurrence rate and longer survival seen in the study group in the present series may have been mediated by the disproportionate number of women with a family history in this group.

Patients in the control group presented with larger and 
histologically more malignant tumours associated with increased axillary lymph-node disease. Women who take contraceptive steroids have more frequent medical examinations, and so possibly their tumours may be diagnosed at an earlier stage. Vessey et $a l,{ }^{6}$ however, reported that $95 \%$ of breast cancers in their study were initially discovered by the patient or her husband. This would seem to argue against detection bias as a reason for the higher proportion of patients with less advanced tumours in the study group. An alternative explanation is that taking contraceptive steroids has a beneficial biological effect on tumour growth and slows the natural progression of the disease.

The significantly improved survival of patients in the study group who were treated by radical mastectomy may in part reflect the lower incidence of axillary node disease; but when differences in nodal disease were excluded by considering only patients with pathological stage I tumours the patients in the study group still survived longer. This again suggests that taking the products may have had some biologically beneficial effect on the tumour. Vessey $e t a^{6}$ studied over 700 women with newly diagnosed breast cancer and also found that women who had not taken oral contraceptives seemed to present with more advanced tumours and that this was reflected in the survival pattern. They also concluded that taking these products might have a beneficial effect on tumour growth and spread. There is certainly no evidence that taking oral contraceptives had any harmful effect, except possibly in patients with a close family history of breast cancer.

We thank Sheila Sexton for help with the statistical comparisons.
Requests for reprints should be sent to $\mathrm{Mr}$ John $\mathrm{L}$ Hayward, Breast Cancer Unit, Guy's Hospital, London SE1 9RT.

\section{References}

${ }^{1}$ Hertz R. The problem of possible effects of oral contraceptives on cancer of the breast. Cancer $1969 ; 24: 1140-5$.

${ }^{2}$ Nathanson IT, Kelley RM. Hormonal treatment of cancer. $N$ Engl f Med $1952 ; 246: 135-45$

${ }^{3}$ Connell EB, Gillespie D, Goodman HC, Heiby JR, et al. Oral contraceptives: update on usage, safety, and side effects. Population reports 1979 January; series A, No 5 .

${ }^{4}$ Vessey MP, Doll R, Sutton PM. Investigation of the possible relationship between oral contraceptives and benign and malignant breast disease. Cancer $1971 ; 28: 1395-9$.

5 Paffenbarger RS, Fasal E, Simmons ME, Kampert JB. Cancer risk as related to use of oral contraceptives during fertile years. Cancer $1977 ; 39$ : 1887-91.

6 Vessey MP, Doll R, Jones K, McPherson K, Yeates D. An epidemiological study of oral contraceptives and breast cancer. Br Med $\mathcal{Y} 1979 ; \mathrm{i}: 1757-60$.

${ }^{7}$ Spencer JD, Millis RR, Hayward JL. Contraceptive steroids and breast cancer. Br Med f 1978; ; :1024-6.

${ }^{8}$ Atkins H, Hayward JL, Klugman DJ, Wayte AB. Treatment of early breast cancer: a report after ten years of a clinical trial. $\mathrm{Br} \mathrm{Med} \mathcal{F} 1972$; ii:423-9.

${ }^{9}$ Bloom HJG, Richardson WW. Histological grading and prognosis in breast cancer. A study of 1409 cases of which 359 have been followed for 15 years. Br $\mathcal{F}$ Cancer 1957;11:359-77.

${ }^{10}$ Anderson DE. Some characteristics of familial breast cancer. Cancer 1971; 28:1500-4.

${ }^{11}$ Langlands AO, Keer GR, Bloomer SM. Familial breast cancer. Clin Oncol $1976 ; 2: 41-5$.

(Accepted 16 December 1980)

\title{
Unilateral outward-turning leg in infancy
}

\author{
ROLFE BIRCH, JULIAN WENGER
}

\begin{abstract}
An unreported condition of the legs in infants was found in more than 130 children referred to one hospital from 1973 to 1979 . One hundred of these children were studied. One leg, usually the right, lay in external rotation. Although there was no loss or restriction of movement at the hip joints, in most cases there was a difference in the arc of rotation. Eleven children also had mild hooking of the forefoot on the unaffected side. Hip radiographs were normal in all cases. Obstetric records were reviewed in 70 cases, but no relation was found between presenting position at birth and side of the affected limb. The condition resolved spontaneously in most of the children who were followed up.

This condition may cause anxiety to parents and doctors but it seems to be a variant of normal with an excellent prognosis.
\end{abstract}

\section{Introduction}

From 1973 to 1979 over 130 infants have been referred to Queen Mary's Hospital for Children, Carshalton, with a previously unreported condition of the legs. The condition is characterised by one leg, usually the right, lying in external rotation. This is often most obvious when the child is seated on the mother's knee. We present here details of the first 100 cases.

\section{Patients and methods}

All 100 children in this study were first seen and examined by $\mathrm{Mr}$ Geoffrey Walker, who recognised this condition about 10 years ago. Eighty-four cases were reviewed by the authors; the remaining 16 were seen by other doctors and reassessed by means of a questionnaire.

A birth and development history was taken in each case and a full orthopaedic examination made. We were particularly interested in the range of hip rotation, which was measured with the hips extended. A hip radiograph was available for all the children. Obstetric records were reviewed in 70 cases. Any child with a general disorder, such as cerebral palsy, or with clinical or radiological evidence of hip dysplasia was excluded from this study.

\section{Results}

Clinical signs and radiographs-The striking finding was that in 86 children ( 53 boys, 33 girls) the right leg was affected. Forty-six were firstborn. Thirty-five presented to the orthopaedic clinic at 